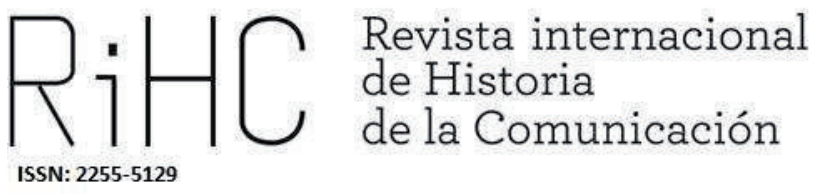

\title{
LA INDUSTRIA DE LA RADIO ESPAÑOLA EN SUS ORÍGENES. UNA VISIÓN A TRAVÉS DE LA PUBLICIDAD EN LA REVISTA ONDAS
}

The Spanish radio industry in its origins. A vision through advertising in Ondas magazine

DOI: http://dx.doi.org/10.12795/RiCH.2021.i17.07

Recibido: 3-11-2021

Aceptado: 3-12-2021

Juan Carlos Rodríguez-Centeno

Universidad de Sevilla, España

jcrodri@us.es

ORCID (D) 0000-0002-6838-6064 
Resumen: En el año 2023 se cumplen cien años del nacimiento de la radio comercial en España, un nuevo medio de comunicación que transformaría la vida cotidiana de los españoles. Los inicios de la radio en nuestro país fueron difíciles por las dificultades técnicas y la precariedad económica. Esta situación cambió con la aparición de Unión Radio, una emisora que en pocos años integraría la mayoría de estaciones de radio existentes en las grandes ciudades de España: Madrid, Barcelona, Sevilla, Salamanca, Cádiz, entre otras. Los principales fabricantes internacionales de aparatos de radio fundaron en 1925 la emisora Unión Radio de Madrid y la revista Ondas. Ambos medios fueron utilizados como plataformas publicitarias para la promoción de sus productos. Los fabricantes entendieron que para que el producto-radio tuviera éxito debían desarrollar el servicio-radio. Este trabajo analiza los anuncios publicitarios de la revista para observar los componentes de la industria radioeléctrica en sus orígenes y la evolución en sus primeros años. Hemos tomado como referencia temporal los años 19251926 y 1929-1930 para realizar un análisis comparativo. Una de las principales conclusiones es que el mercado español de productos de radio estaba dominado por marcas extranjeras, y que la producción española era insignificante.

Palabras clave: Radio, publicidad, industria, historia medios.

\begin{abstract}
Spain: a hundred years ago, a new communication method that would change the spaniards daily life was born. The beginnings of radio in our country were tough due to the technical difficulties and the economical crisis. The beginnings of radio in our country were difficult due to technical difficulties and economic precariousness. This situation changed with the appearance of Unión Radio, a radio station that in a few years would integrate most of the existing radio stations in the large cities of Spain: Madrid, Barcelona, Seville, Salamanca, Cádiz, among others. The main radio-machines manufactorers founded the Unión Radio de Madrid station and the Ondas magazine in 1925. Both were used as advertising platforms to promote their products. The manufacturers understood that for the radioproduct to be successful they had to develop the radio-service. This work analizes the magazine's advertisements in order to observe the radioelectric industry components in its begining, and its evolution in its early years. We have chosen the years 1925-1926 and 1929-1930 as a temporal reference to make a comparative analysis. One of the main conclusions is that the spanish radio products market was dominated by foreign brands, and that the spanish production was insignificant.
\end{abstract}

Keywords: Radio; advertising; industry; media history.

\title{
Introducción
}

El 17 de junio de 1925 se inauguraba la emisora Unión Radio de Madrid. Como señala su número de licencia oficial, EAJ-7, otras seis estaciones la precedieron en la historia de un medio de comunicación, la radio, que iba a transformar la vida cotidiana de la sociedad española al igual que la estaba modificando en todo el mundo. Radio Barcelona, Radio España (Madrid), Radio Cádiz, Radio Castilla (Madrid) y Radio Club Sevillano habían comenzado sus emisiones unos meses antes que Unión Radio, y a 
finales de 1925 ya existían 25 emisoras repartidas por las principales ciudades de España. En este sentido, como señala Ángeles Afuera "el menudeo de emisoras pequeñas y de pocos recursos que habían ido aflorando en todo el territorio español no significaba diversidad de emisiones, porque éstas eran esporádicas y de mala calidad de sonido" (2021: 41). Esta precariedad unida a la aprobación de la Orden de 15 de abril de 1925 por la que se permitía a las empresas propietarias de licencias de radio transferirlas a otras empresas, permitió a Unión Radio iniciar un proceso de adquisición y fusión, de tal forma que a mediados de 1928 ya se había hecho con el control de sus principales competidores, integrando algunas emisoras (Radio Barcelona, Radio Cádiz, Radio Sevilla, Radio Salamanca, etc.) y suprimiendo otras (Radio Castilla, Radio Ibérica ${ }^{1}$ ). Esta estrategia "situaría a la cadena Unión Radio al final de la dictadura de Primo de Rivera en el primer y único grupo radiofónico español" (Balsebre, 2001: 127).

En el mismo mes de junio de 1925 aparece la revista Ondas, "Órgano oficial de Unión Radio", como rezaba en su cabecera. Tenía una periodicidad semanal, un precio de cuarenta céntimos el número y veinte pesetas la suscripción anual. No era la primera revista especializada en el medio radio; anteriormente habían aparecido Radio-Sport, Tele-Radio, Radiosola, Radio Ciencia Popular y T.S.H. Esta última era el órgano de la Federación Nacional de Aficionados y "portavoz en la temporada 1924-1925 de los intereses económicos contrarios al grupo promotor de la emisora Unión Radio" (Balsebre, 2001: 51). La revista cumplía varias funciones: una primera, la más evidente, informar sobre la programación de la emisora matriz, y de las emisoras que se fueron sumando a la cadena. Una segunda función era mantener un vínculo con las audiencias, que en aquellos años iniciales estaba formada en su gran mayoría por radioyentes especializados, con conocimientos técnicos sobre el medio y que provenían de clubes de radioaficionados. A ellos iban dirigidos los reportajes sobre los avances e innovaciones tecnológicas. En el segundo número la revista incluía esta apelación, "Todos los radioescuchas españoles deben prestar su apoyo moral y material a la revista Ondas, porque ella aspira a convertirse en legitimo portavoz de la radiodifusión"2. Esto enlaza con otro objetivo, la revista debía servir de altavoz editorial de la cadena, especialmente en un periodo de enfrentamiento que desembocó en "la campaña que contra Unión Radio como futuro monopolio habían desatado, principalmente, el diario La Libertad, la revista TSH y la asociación ARE" (Garitaonaindía, 1988: 35). El último objetivo de la revista estaba relacionado con la financiación de la emisora y la propia revista. El Reglamento del 14 de junio de 1924 "establecía tres formas de financiación para las emisoras legalizadas y registradas en España: las cuotas voluntarias de

\footnotetext{
${ }^{1}$ Radio Ibérica fue la pionera de la radiodifusión española en 1923. Sin embargo, cuando en 1924 se aprueba el "Reglamento para el establecimiento y régimen de estaciones radioeléctricas particulares" que obliga a las emisoras a solicitar una licencia oficial, Radio Ibérica se retrasa en la petición y se le adelantan cinco estaciones, así pues su indicativo oficial sería EAJ-6.
}

2 (Ondas, 28-VI-1925: 6) 
miembros de asociaciones de radioyentes, la venta de revistas y la publicidad" (Afuera, 2021: 45). Es decir la revista debía convertirse en un pilar económico de la cadena, máxime cuando el propio Reglamento en su artículo 22 limitaba la publicidad a un máximo de cinco minutos por hora emitida, un límite que restringía de forma notable los ingresos por esta vía. A su vez la revista tenía dos fuentes de financiación, las ventas al número y por suscripción, y los ingresos por los anuncios insertos. Desde los inicios la presencia de los reclamos fue abundante, el primer número incluyó diez anuncios de distintos tamaños, siendo la página entera, la columna y el faldón los formatos más habituales. El número de anuncios fue aumentando a medida que el medio crecía en audiencia, y a la par, también crecía la industria de productos radioeléctricos, de tal forma que a finales de la década de 1920 encontramos algunas ediciones con una veintena de reclamos. Si tenemos en cuenta que la revista tenía treinta y dos páginas, podemos estimar que la publicidad tenía una presencia muy notable ${ }^{3}$.

La revista Ondas, como ya hemos señalado es una revista especializada, dirigida a un público especializado, o al menos iniciado e interesado en un medio que se caracterizaba en sus primeros pasos por la complejidad técnica. En consecuencia, la publicidad de la revista era una publicidad especializada promocionada por la industria de la radiotelefonía ${ }^{4}$. El objetivo de nuestro trabajo es analizar la publicidad inserta en la revista Ondas en sus primeros años para observar la estructura de la industria de la radio y su evolución en España, pero no en su dimensión como radio-servicio (emisoras y cadenas), sino en su vertiente radio-producto (los aparatos receptores y sus complementos); es decir, nos interesa conocer quiénes eran las empresas fabricantes, distribuidoras y vendedoras, qué productos comercializaban, los precios de esos productos, a quiénes se dirigían, y cómo eran los argumentos persuasivos utilizados para su promoción.

\section{Estado de la cuestión}

Nuestra investigación se centra en el periodo histórico del nacimiento y los primeros años del medio radio en España, es decir la década de 1920 del siglo pasado. Las obras referenciales que abarcan esta etapa son La historia de la radio en España. Volumen 1. (1874-1939), edición de 2001, de Armand Balsebre; La radio en España. 1923-1939. De altavoz musical a arma de propaganda (1988), de Carmelo Garitaonaindía; La radio en

\footnotetext{
3 Ángeles Afuera (2021: 50) reproduce un acta del Consejo de Administración de Unión Radio con los ingresos publicitarios de los primeros seis años. Las cifras en los años completos son 78.775 (1926), 95.790 (1927), 76.112 (1928) y 86.071 (1929).

${ }^{4}$ Antes de que el medio fuese conocido popularmente como "la radio", su nombre genérico era telefonía sin hilos (tsh) y posteriormente radiotelefonía.
} 
España (1896-1977). Una historia documental (2007), de Ángel Faus; La radio (de la telegrafía sin hilos a los satélites) (1780-1984), de Rosa Franquet y Josep María Martí, edición de 1985; y el volumen colectivo 1924: el nacimiento de la programación radiofónica en España, de Ventín Pereira, Rodríguez Barba, Fernández Sande y Peinado Miguel. También es reseñable por sus aportaciones, aunque con un tratamiento redaccional más cercano a lo periodístico que a lo académico, la obra de Lorenzo Díaz La radio en España. 1923-1997 (1997).

En relación al estudio específico de Unión Radio resulta esencial la reciente publicación Aquí, Unión Radio. Crónica de la primera cadena española (1925-1939), de Ángeles Afuera, editada en 2021. En el año 1999, en conmemoración del septuagésimo quinto aniversario de la aparición del medio en España, la Cadena Ser editó el monográfico En el aire. 75 años de radio en España, con importantes testimonios de protagonistas y una fuente de consulta de datos muy estimable. También es de obligada consulta la obra de Manuel Fernández Sande Los orígenes de la radio en España. Volumen 2. La competencia entre Unión Radio y Radio Ibérica (1925-1927), publicado en 2006.

Para ilustrar el recorrido personal y profesional del pionero en el medio, Antonio Castilla, es recomendable la consulta del libro de Antonio Checa Historia de la radio en Andalucía (1917-1978), editado en el año 2000; y el monográfico Pioneros de la radio, de José Manuel Salillas, editado por el propio autor en 1988.

El estudio de las revistas radiofónicas surgidas en los años iniciales del medio no ha sido abordado en profundidad, lo cual abre una línea de investigación futura. Encontramos numerosas referencias en la bibliografía consultada, tanto de la revista Ondas como de sus coetáneas, pero no estudios monográficos. Asimismo, tampoco encontramos investigaciones de relevancia centradas en la publicidad inserta en estas revistas, exceptuando el artítulo Orígenes de la autopublicidad radiofónica. Cómo vender un nuevo medio, de Ángeles Afuera, de reciente publicación en la revista Documentación de las Ciencias de la Información (2021), donde analiza las campañas publicitarias de Unión Radio en la revista Ondas. En consecuencia, es este trabajo un primer eslabón de una serie de investigaciones que actualmente están en proceso y que nos permitirán colaborar en la reconstrucción de los orígenes y evolución de la radio utilizando la publicidad como documento histórico.

\section{Metodología}

En nuestra investigación utilizaremos técnicas mixtas cuantitativas y cualitativas. En el primer caso seleccionaremos los ejemplares de la revista Ondas conservados en la Hemeroteca Digital de la Biblioteca Nacional de España, y los dividiremos en dos etapas. 
La primera abarca el primer año de vida de la publicación, un periodo comprendido desde el 1 de junio de 1925, fecha de salida, y el 27 de junio de 1926. La segunda etapa seleccionada corresponde a las fechas entre el 1 de junio de 1929 y el 31 de mayo de 1930. La comparación entre estas dos etapas separadas por cinco años nos permitirá analizar la evolución de la industria de la radio.

Existen problemas para datar la salida a la venta del primer número de la revista. En el ejemplar consultado en la Hemeroteca Digital de la Biblioteca Nacional de España aparece la fecha del 1 de junio de 1925. Sin embargo, existen diferencias entre los investigadores consultados. Ángeles Afuera (2021: 48) coincide en el 1 de junio, en cambio Armand Balsebre (2001: 144), Lorenzo Díaz (1997: 129) y Carmelo Garitaonaindía (1988: 28) afirman que fue el 21 de junio. El problema tiene su origen en el ejemplar de la Hemeroteca Digital: si bien en la portada aparece la fecha de 1 de junio, en las páginas 27 y 28 , en una sección que lleva por título "Algunos Testimonios", se recogen cartas dirigidas al director fechadas entre el 7 y el 23 de junio de 1925; es decir que dicho ejemplar no pudo estar a la venta ni el 1 ni el 21 de junio. Una posible solución a este problema puede estar en la página número 3, donde podemos leer: "La extraordinaria acogida que ha tenido nuestro primer número nos ha colmado de satisfacción... El lunes a primera hora de la mañana se había agotado nuestra edición y no pudimos complacer los pedidos que con insistencia se nos hacían lo mismo de Madrid que de provincias". En vista de estos datos podemos aventurar que el primer ejemplar salió a la venta el lunes 1 de junio, se agotó, y ante la creciente demanda volvió a editarse con la misma fecha y con las cartas añadidas, y salió a la venta con posterioridad a la fecha del 23 de junio. En consecuencia, el ejemplar de la Hemeroteca Digital corresponde a esta segunda edición del primer número.

Los ejemplares consultados en la primera etapa (1925-1926) son 54, y en la segunda etapa (1929-1930) son 53, que suman una cantidad definitiva de 107 ediciones. En relación al número de anuncios seleccionados, una vez descartados los reclamos repetidos en distintas ediciones, ascienden a 114 en la primera fase de estudio y 123 en la segunda fase, lo cual suma una cifra de 237 anuncios.

Para el estudio cualitativo efectuaremos un análisis de contenido y sobre la muestra seleccionada aplicamos previamente los siguientes ítems: anunciante, producto, marca, precio, públicos-objetivos, eslogan publicitario y tipología persuasiva. En este último caso diferenciamos entre argumentación racional (por ejemplo, la descripción técnica de un receptor de radio) y argumentación emocional y simbólica (apelaciones al estatus social del destinatario). Para el análisis de las emociones en los reclamos publicitarios tomaremos como referencia la monografía de Belén López Vázquez de 2007, Publicidad emocional. Estrategias creativas. 


\section{Anunciantes}

\subsection{Grandes Corporaciones}

El primer anuncio inserto en la revista corresponde a la compañía SICE ${ }^{5}$. Estas siglas correspondían a la Sociedad Ibérica de Construcciones Eléctricas, empresa creada en 1921 y que actuaría en España como filial de la empresa norteamericana Radio Corporation of América (RCA). Esta firma, a su vez, pertenecía a las tres compañías estadounidenses más importantes en la fabricación y comercialización de aparatos de radio y complementos: General Electric, AT\&T y Westinghouse. En 1926 la RCA crearía la mayor cadena de emisoras de radio de Estados Unidos, la NBC. Una vez creada Unión Radio, la SICE tendría una importante representación en el Consejo de Administración de la emisora: Luis Sánchez Cuervo ocuparía una de las dos vicepresidencias. Es decir, a través de su filial española, la RCA formaba parte del accionariado de Unión Radio. En octubre de 1925 RCA/SICE publicaban un anuncio ${ }^{6}$ donde cifraban en "más de 450 millones de pesetas" el montante por la "venta de estos aparatos en 1924" y que "esta cifra excede en $2 / 5$ al resto de toda la venta mundial".

El segundo anuncio ${ }^{7}$ aparecido en el primer número corresponde a la empresa Sociedad Española de Acumuladores Tudor, creada a finales del siglo XIX como filial de las firmas Société d'Accumulateur Tudor (Francia) y Accumulatoren Fabrik AG -AFA- (Alemania), fabricantes de las célebres baterías creadas por Henri Tudor, que serían trascendentales para el desarrollo de las industrias del automóvil, de la aviación y de la radio, entre otras. La filial española de la firma Tudor tenía dos vocales en el primer Consejo de Administración de Unión Radio.

En otro de los reclamos publicitarios que encontramos en esta primera edición aparece la Compañía Nacional de Telegrafía sin Hilos (CNTSH), "propietaria en España de las patentes Marconi" ${ }^{2}$. La empresa británica Marconi's Wireless Telegraph Company había sido fundada por Guillermo Marconi en los últimos años del siglo XIX; en diciembre de 1910 constituyó en España la filial CNSTH, con la que obtuvo en 1911 el monopolio de la telegrafía en España. Entre los socios fundadores de Unión Radio encontramos a la CNTSH que obtendría una vicepresidencia y una vocalía en su primer Consejo directivo.

\footnotetext{
${ }^{5}$ (1-VI-1925: 3). Todos los anuncios proceden de la revista Ondas. Para no hacer excesivamente reiterativa la aparición del título, a partir de ahora omitiremos el nombre de la revista en las referencias.

${ }^{6}(18-X-1925: 18)$

7 (1-VI-1925:14)

8 (1-VI-1925: 18)
} 
La sociedad anónima Electrodo anunciaba en este primer número sus "aparatos eléctricos y piezas sueltas" ${ }^{\prime \prime}$. Esta empresa de capital nacional agrupaba a comerciantes del sector y tenía dos vocales en el máximo órgano de dirección de la emisora madrileña.

La Societé Francaise Radio-Électrique (SFR) se fundó en 1910, y agrupaba a la mayoría de los constructores de productos radioeléctricos de Francia. En noviembre de 1922 la SFR inauguraba en París, Radiola, la primera emisora privada de Europa. La marca Radiola no solo daba nombre a la emisora, también a los aparatos de emisión y recepción fabricados por la SFR. Dos años más tarde de la inauguración de la emisora, los directivos decidieron cambiar el nombre de la estación de radio, que pasaría a llamarse Radio París y concentrar la marca en los productos radioeléctricos. La Societé Francaise Radio-Electrique, la marca Radiola y seis de sus aparatos receptores aparecen en un anuncio ${ }^{10}$ a toda página en el número inaugural de Ondas. En el accionariado de Unión Radio participaba con dos vocales la empresa española Omnium Ibérico Industrial, filial de SFR.

La contraportada del primer número de la revista contiene un anuncio de la Compañía General Española de Electricidad ${ }^{11}$, que tenía una vocalía en el Consejo de Administración de Unión Radio.

En la edición número sexta de Ondas encontramos un reclamo ${ }^{12}$ de AEG Ibérica de Electricidad, empresa filial de la alemana Allgemeine Elektricitäts-Gesellschaft (AEG), creada en 1883, fabricante y comercializadora de la marca Telefunken, "conocida en todo el mundo como una de las que más han contribuido al desarrollo de la Telegrafía y Telefonía sin hilos". La empresa germana a través de su filial española disponía de dos vocales en el máximo órgano de representación de la emisora.

Para encontrar los primeros anuncios de Teléfonos Bell tendrían que trascurrir unos meses. A partir de febrero de 1926 sus productos (receptores y altavoces) comenzarían a aparecer con cierta frecuencia entre las páginas de la publicación. Teléfonos Bell s.a. se fundó en Barcelona en 1922, como empresa filial de la norteamericana Western Electric, que pertenecía a su vez a una de las multinacionales más poderosas del mundo, la ITT. La filial española controlaba dos vocalías en el Consejo. La presencia como anunciante de Teléfonos Bell apenas duró un mes debido a la decisión de la empresa matriz de cambiar de nombre a todas las filiales internacionales. En España la nueva

\footnotetext{
9 (1-VI-1925: 28)

10 (1-VI-1925: 29)

11 (1-VI-1925: 32)

12 (26-VII-1925: 29)
} 
marca corporativa se llamó Standard Eléctrica y su primer anuncio apareció en marzo de $1926^{13}$.

Los principales fabricantes mundiales de aparatos y material radioeléctrico, a través de sus filiales españolas, fundaron Unión Radio "con la vocación de constituirse en "cabeza de playa" del desembarco en España del grupo de intereses multinacionales que buscaba el control del negocio de la radiodifusión en España" (Balsebre, 2001: 126). Al igual que habían hecho en los países más avanzados económica y tecnológicamente (EEUU, Francia, Reino Unido, Alemania) las grandes corporaciones, que habían inventado el producto-radio, decidieron impulsar en España el servicio-radio, conscientes de un hecho indudable: sin el avance del servicio, el negocio del producto no tenía futuro. Y el negocio en los años veinte de la industria radioeléctrica consistía en vender receptores, altavoces, baterías, pilas, y una larga lista de productos en una economía, la española, que gracias a la neutralidad en la Gran Guerra Europea vivía años de bonanza.

En este sentido, Unión Radio y la revista Ondas, es decir el servicio-radio, además de otras funciones, debían ser plataformas publicitarias de las corporaciones para el desarrollo del negocio producto-radio.

\subsection{Distribuidores/vendedores}

Los grandes anunciantes distribuían sus productos a través de sus propias oficinas, puntos de venta y almacenes. Pero hubo otras muchas marcas, la mayoría extranjeras, que sin el potencial económico de las corporaciones citadas no podían (o les resultaba poco rentable) implementar una propia red logística, por lo cual llegaron a acuerdos de distribución con empresas españolas que ya tenían experiencia en el mercado de la radiotelefonía sin hilos. Una gran mayoría de distribuidores eran independientes, es decir vendían en libre competencia con otros establecimientos las mismas marcas, aunque también hemos encontrado distribuidores exclusivistas, aquellos que llegaban a acuerdos con una sola o varias marcas que no se vendían en otros puntos de venta.

A continuación haremos referencia a aquellos que tuvieron una mayor presencia publicitaria en la primera etapa estudiada (1925-26) y sus principales marcas: Radio Electra (Eureka, Thompson, Ericsson, Far, Brown, Sterling), Casa Ricardo (The Mighty Atom, Revo), Jaime Schwab (Nora, Hallophon, Pertrix), Pablo Zenker (Brunet), Radio Nacional (Berrens, Bardon, Radiosita, Zeiler), Viuda y Sobrinos de R. Prado (Hellesens, Ericsson).

\footnotetext{
${ }^{13}$ (7-III-1926: 21)
} 
En la segunda etapa (1929-30) permanecen la mayoría que hemos reseñado en la primera, y aparecen: Vivó, Vidal y Balasch (Mysöl, Hydrawerk, Membra, Baltic, Nichrome), F. Montojo (Vatea), Sánchez Ramos y Simonetta (Grillet, Nord, Musicalpha, Leclanché), Vivomir (Warner, Philarmonicus, Valvo, Silver).

\subsection{Un caso excepcional}

La marca Castilla suponía un caso excepcional por varios motivos. El primero por ser un anunciante español entre una mayoría foránea, el segundo por anunciar que sus productos eran de "fabricación netamente española" cuando sus competidores presumían en sus reclamos de la procedencia de sus productos: París, Berlín, Londres, Hamburgo, "Stockolm" o "producto americano". Y el tercer motivo es la persona que prestó su apellido a la marca. Antonio Castilla fue una de las personalidades más relevantes de los inicios de la radiodifusión en España. Fue discípulo y ayudante del gran pionero del medio en España, Matías Balsera, y tras años experimentando en la comunicación telegráfica, "siente la necesidad de viajar para ampliar conocimientos fuera de España, lo hará en Francia, Gran Bretaña y finalmente EEUU, donde obtiene el título de ingeniero en radioelectricidad" (Checa, 2000: 10-11). Con tal bagaje y de regreso a España, en 1917 participó en la fundación de la Compañía Ibérica de Telecomunicación, una empresa que inició sus trabajos de tecnología para las comunicaciones del Ejército. En 1920 las tres emisoras de radiotelegrafía "que albergan los primeros ensayos radiofónicos en España tienen su sede en Madrid, son de titularidad oficial y han sido construidas total o parcialmente por Antonio Castilla" (Balsebre, 2001: 25). Tres años después participaría en la creación de la primera emisora española, Radio Ibérica. Apartado por sus socios del proyecto, fundaría Radio Castilla en octubre de $1924^{14}$, la cuarta emisora oficial del país, aunque tendría una vida efímera ya que fue adquirida por Unión Radio el 1 de mayo de 1926 y desmantelada en abril de 1927. La venta de Radio Castilla llevaría a su propietario a ser el máximo accionista de Unión Radio, ya que el pago se hizo en acciones y bonos. Sin embargo "el papel de Castilla en Unión Radio no se correspondió nunca con esa realidad" (Faus, 2007: 313), debido a que los títulos recibidos estaban exentos de representación en los órganos de gobierno de la cadena, es decir Antonio Castilla era una figura simbólica sin poder de decisión. A partir de entonces se dedicó al desarrollo empresarial de sus negocios de material radioeléctrico.

Los anuncios de la marca Castilla comenzaron a proliferar en la revista a partir de septiembre de 1925. Su primer anuncio ${ }^{15}$ fue de lámparas para radiotelefonía, y en el mismo podemos ver la dirección de la fábrica y las oficinas, calle Áncora número 6, la

\footnotetext{
${ }^{14}$ Tardaría un año en emitir de forma regular, en octubre de 1925.

${ }^{15}$ (13-IX-1925: 11)
} 
misma dirección donde tenía su sede la emisora Radio Castilla. A finales de la década Antonio Castilla crea la Industria Nacional de Radio, para la fabricación, y los Establecimientos Castilla, para la distribución y venta "netamente española de toda clase de válvulas receptoras y emisoras insuperables en calidad y precios"16, con sede en la calle General Pardiñas de Madrid.

\section{Productos y marcas}

La Teleaudición, un establecimiento vendedor de "material de radio garantizado" publicó un anuncio ${ }^{17}$ donde podemos ver más de una veintena de productos distintos. La oferta abarcaba desde los aparatos más habituales y dirigidos a un público amplio, como receptores, cascos, altavoces y antenas de cuadro; complementos como acumuladores y transformadores; hasta piezas de montaje dirigidas a expertos como conmutadores, aisladores, resistencias, etc. En este trabajo, debido a las dimensiones, nos centraremos en aquellos productos de uso más extendido y común, y por este motivo, más publicitados. Asimismo haremos continuas referencias a los precios, y para tener una perspectiva del coste de estos productos en su contexto económico temporal utilizaremos el Anuario de 1930 donde se registran los salarios de las clases obreras en $1929^{18}$. Según este informe los sueldos oscilaban entre las 150 y las 500 pesetas al mes. En el rango superior (300-500) encontramos auxiliares de farmacia, dependientes, confiteros y panaderos, biseladores de lunas, estereotipadores y electricistas, entre otros. Los trabajadores con menos remuneración (150-200) eran las bordadoras, gorreras, peones camineros, y obreras en cajas de cartón ${ }^{19}$.

\subsection{Receptores}

Primera etapa: A mediados de la década de 1920 la industria de la radiodifusión española, desde un punto de vista técnico, se encontraba en una fase de transición de la radio de galena a la radio de válvulas (o lámparas). La convivencia de ambas se corrobora en los anuncios encontrados durante las primeras ediciones, con reclamos donde se ofertaban solo las primeras (Siceola, Marconiphone, Ericsson), en otros donde

\footnotetext{
${ }^{16}$ (6-XII-1930: 29)

17 (6-IX-1925: 12)

18 El salario y la jornada en Madrid. https://www.ine.es/inebaseweb/pdfDispacher.do?td=45719. Consultado el 24/10/2021.

${ }^{19}$ Las obreras de cajas de cartón cobraban 5 pesetas el jornal. Los obreros de cajas de cartón cobraban 12 pesetas. Esta diferencia de más del doble se producía también en otros oficios.
} 
solo aparecen ofertas de las segundas (Radiola), y en otros donde la oferta es conjunta (Electrodo).

Los receptores de galena tenían un precio mucho más asequible que sus rivales de válvulas. Algunas tiendas especializadas ofrecían aparatos sin marca desde 5 hasta 20 pesetas. La firma Electrodo se adquiría por 18 pesetas. El modelo más barato de Marconi (M.C.1) costaba 10 pesetas, y el más caro (Baby), ascendía a 50; y por este mismo precio la empresa SICE comercializaba su modelo de fabricación nacional Siceola.

Los receptores de válvulas que se comercializaban en 1925 eran de varios tipos y precios, dependiendo del número de lámparas que portasen. A mayor número de válvulas, más capacidad y mayor calidad en la recepción. Los modelos más básicos tenían entre una y tres unidades, algunos eran genéricos (es decir sin marca, construidos artesanalmente o importados). En la tienda Radio Electra podían encontrarse el modelo de dos válvulas a 210 pesetas y el de tres a 295. Como es evidente los modelos con marca encarecían su precio: el Radiola de tres válvulas tenía un precio de 325 pesetas y el Telefunkon 3 ascendía a 535. Las innovaciones técnicas se sucedían de forma dinámica, las marcas competían por introducir los nuevos receptores con las últimas novedades que mejoraban las audiciones. A principios de 1926 ya podemos encontrar anuncios con ofertas de aparatos con cuatro válvulas. Los genéricos se ofertaban por 475 pesetas y la marca J.H. Berrens ofrecía dos modelos al precio de 493 y 899 pesetas. A mediados de año ya se anunciaban aparatos de seis y ocho válvulas.

Existían muchas diferencias entre los aparatos de galena y los de válvulas: los primeros como hemos visto eran más baratos, con menor complejidad técnica y menos complementos, con muchas limitaciones para sintonizar emisoras alejadas y una calidad de audición baja, sensibles a interferencias de todo tipo. Pero la mayor diferencia radicaba en la forma de "oír la radio". Los receptores de galena necesitaban para su escucha el acople de auriculares o cascos. Es decir, la forma de exposición al medio era individualizada, heredera de los radioaficionados, que obligaba al oyente a permanecer sentado próximo al receptor y le imposibilitaba compaginar la escucha con la realización de otras actividades. La introducción de los aparatos de válvulas multiplicó la potencia receptora, permitió conectar altavoces y facilitar un cambio sustancial en la breve historia del medio: liberó a los oyentes de los cables que le mantenían atado al receptor y socializó la escucha. Mediada la década de los veinte del siglo XX los aparatos de galena eran el pasado, los de válvulas eran el futuro, y mientras estos evolucionaban técnica y estéticamente, los primeros se mantenían en el mercado únicamente por sus bajos precios. De forma paulatina los receptores de galena fueron despareciendo de la publicidad, de tal forma que en 1930 ya no los encontramos en las ofertas comerciales de los anunciantes. Algunas marcas llegaron a lanzar modelos híbridos, aparatos de galena con una o dos válvulas, como el modelo Arcon DR de Telefunken (225 ptas.) y el Siceola II de SICE (316 ptas.) paro no tuvieron mucha acogida. 
Como hemos apuntado las ventajas de la recepción a través de los aparatos de válvulas eran dos: la libertad de movimientos y la escucha compartida. Como ocurriría a partir de la década de los sesenta con la televisión, la audición conjunta o socializada modificó los espacios y hábitos de convivialidad en los hogares. El receptor iría ocupando un lugar preminente en los salones y comedores, y las voces de los "speakers" fueron adquiriendo un mayor protagonismo en la vida familiar. Los fabricantes asumieron las nuevas condiciones y advirtieron un cambio significativo, los aparatos no solo debían cumplir las continuas exigencias técnicas como antes, ahora había que añadir el aspecto estético. Es decir, el receptor no es solo una máquina, es también un objeto decorativo que ocupa un lugar privilegiado en los hogares. Las imágenes de los primeros receptores comercializados eran artefactos futuristas que dejaban a la vista todo un entramado de cables, interruptores, componentes eléctricos, etc. Los nuevos aparatos se "amueblaron", es decir ocultaron todo el utillaje técnico en el interior de un diverso mobiliario donde primaba la belleza y la elegancia. Estos muebles-receptores ocupaban el nivel más alto de precios en la gama de productos de una marca, así el modelo R. Súper VIII de Arsmtrong (RCA) se ofertaba en 3.079 pesetas frente al modelo más económico, un dos válvulas por 293 pesetas. La combinación de diseño y alto coste convirtieron estos productos en objetos de distinción social. El fabricante J.H. Berrens entendió el significado simbólico de estos aparatos y denominó a sus dos modelos superiores como "gran lujo" (1.390 y 1.559 ptas. cada uno).

Mientras la gama alta se posicionaba en las coordenadas del lujo, la belleza y el estatus social, los aparatos de gama intermedia apoyaban sus argumentos publicitarios en descripciones técnicas (Telefunkon 3) y como las innovaciones solucionaban problemas en la recepción (Gaumont):

- Anuncio Telefunkon 3: "De tres lámparas, circuito réflex, amplificación de alta y doble baja, escala de ondas entre 250-700 m., con regulador de calefacción para cada lámpara, interruptor y voltímetro con conmutador selector para la corriente de calefacción, dos discos graduados con tornillos micrométricos para la sintonía primaria y secundaria, acoplo de reacción; todo montado sobre caja de forma pupitre" 20 .

- Anuncio L. Gaumont: "Aparato de gran rendimiento para recepciones a largas distancias. Gran facilidad de regulación y eliminación de párasitos"21.

La audición compartida no solo se produjo en el interior de los hogares. Como no todas las personas podían permitirse la adquisición de los modernos aparatos de válvulas, las marcas facilitaron las escuchas públicas y colectivas, como vemos en estos anuncios: "Oiga las emisiones de Unión Radio en la sala de audiciones "Radiola". Edificio del Banco

\footnotetext{
${ }^{20}$ (6-XII-1925: 17)

${ }^{21}$ (4-IV-1926: 4). Los parásitos se acumulaban en las rejillas de los receptores y podían llegar a obstruirlas, con el siguiente deterioro en la audición.
} 
de España. Entrada por Arlabán, 7"22. La Casa Gaumont, sita en Atocha 90, programaba "audiciones todos los días" además de proporcionar "consejos técnicos gratuitos para el montaje de toda clase de receptores y esquemas" 23 .

La finalidad de estas audiciones públicas eran de tipo promocional que beneficiaban a las marcas y comerciantes, estos oyentes eran potenciales compradores; y a las emisoras, que popularizaban sus programas y fidelizaban a las audiencias. Aunque tampoco hay que desdeñar la finalidad social, facilitar el acceso a un medio de comunicación emergente a la población de menos recursos económicos.

También se producían recepciones radiofónicas en grupo en centros sociales, recreativos, de restauración y ocio. Los fabricantes diseñaron productos destinados a estos lugares dotados de mayor potencia, y en consecuencia mucho más costosos, como el R-X de Armstrong (RCA) "especial para casinos y sociedades, completo, incluido altavoces. Ptas. 1.321"24.

Segunda etapa: Si en la anterior etapa se produjo la transición del receptor de galena al de válvulas, en esta se produce la transición de las fuentes de energía: de los aparatos de baterías (o acumuladores) y pilas a los receptores conectados a la corriente eléctrica. En la frontera entre la década de los veinte y los treinta, el presente y el futuro inmediato eran los receptores con conexión directa a la red eléctrica, "conecte simplemente a la corriente y escuche. Ningún acumulador o pila que cargar, cuidar o cambiar" 25.

En los mercados tecnológicos la irrupción de innovaciones significativas se traduce en la aparición de productos de alto precio por dos motivos principales: uno, se repercuten los costes de una alta inversión en el desarrollo, diseño y fabricación; y dos, la existencia de un grupo de consumidores ávidos de nuevas tecnologías para quienes el precio no supone una barrera para su adquisición. Por ejemplo, el modelo eléctrico más moderno de Philips, con cinco válvulas, se ofertaba por 975 pesetas (a este precio había que añadir los altavoces no incluidos que oscilaban entre las 225 y las 500 pesetas).

Otra consecuencia de las innovaciones tecnológicas es provocar la obsolescencia de la tecnología anterior, en este caso los receptores alimentados con baterías. La lógica del mercado indica que la única manera de competir con productos más avanzados técnicamente es reducir los precios en busca de los consumidores de menor poder adquisitivo y menor exigencia en calidad. De esta forma podemos encontrar aparatos

\footnotetext{
22 (1-VI-1925: 29)

${ }^{23}$ (1-XI-1925: 25)

${ }^{24}$ (18-X-1925: 2$)$

25 (7-IX-1929: 28)
} 
de seis válvulas con baterías con precios inferiores a la etapa anterior: el modelo NewSuper costaba 170 pesetas y el Alter-Super 230.

Una novedad relevante fue la aparición de la mujer como público objetivo de los anunciantes. De hecho, desde la introducción de la radio en los hogares, las mujeres por su posición social como amas de casa pasaban gran parte de la jornada dedicadas a las tareas domésticas, y esto unido a la ampliación horaria de las emisiones configuró al público femenino como un destinatario atractivo para las campañas. Los anunciantes intuyeron que este público no poseía los conocimientos técnicos de parte de la audiencia masculina, así que eliminaron las descripciones prolijas de los aparatos y se centraron en la sencillez técnica y el perfil estético. Veamos este anuncio de un modelo de Telefunken:

Señora, usted, su esposo y sus hijos pueden disfrutar de los encantos de la radio. Escuchar la radio con el Arcolette 3, es cosa fácil y agradable. Basta con una sencilla manipulación en su receptor para gozar de los magníficos programas de radio. El elegante aspecto de su aparato constituye un adorno más para su hogar. ${ }^{26}$

La ampliación de las audiencias hacia perfiles no iniciados hizo que de forma gradual la sencillez y la facilidad en el manejo de los receptores fuera imponiéndose en los mensajes publicitarios a medida que las innovaciones aparecían en el mercado. En 1929 Telefunken introducía el "Selector de estaciones. Suprimiendo la molesta busca de estaciones. Sólo colocar el grado de la emisora deseada y ésta aparecerá" ${ }^{27}$. En otro anuncio podemos ver a una niña de corta edad manipulando un receptor junto al texto: "El más sencillo de todos los receptores. Con un solo mando el Radiola Sfer 29 recibe toda Europa"28. Zenith Radio presentó su modelo con preselección de emisoras a través de botones, "el primero y único receptor automático del mundo. Oprima el botón y allí está su estación" ${ }^{29}$. Otra evolución significativa fue la aparición de receptores compactos, es decir con el altavoz incorporado en el mismo aparato. Para la marca Nora Radio esto era "Lo definitivo. Lo más sencillo. Lo más perfecto" 30 .

La gama alta seguía siendo las radio-muebles, que se adaptaban a las nuevas condiciones a la vez que ofrecían una estética más barroquizante y recargada, a diferencia de la primera etapa, donde los aparatos seguían líneas clásicas y racionalistas. La marca Atwater Kent ofrecía un modelo de madera labrada en este anuncio: "Se sentirá orgulloso y encantado de poseer este regio aparato. En selectividad, alcance,

\footnotetext{
${ }^{26}$ (1-VI-1929: 26)

27 (7-IX-1929: 24)

${ }^{28}$ (2-XII-1929: 31)

29 (2-XII-1929: 27)

${ }^{30}$ (2-II-1930: 28)
} 
volumen, fidelidad y limpieza de sonidos, nada le iguala. Basta conectarlo a la corriente eléctrica. El mueble puede adornar el salón más aristocrático"31.

Algunos anuncios constatan la existencia de un público cosmopolita, culto y políglota a quienes las marcas ofertaban aparatos "para oír las estaciones extranjeras" (Eswe), "todas las estaciones europeas" (Telefunken), "recibe toda Europa" (Radiola), "iQué bien se oyen las audiciones extranjeras!" (J.H. Berrens). Incluso había marcas que además de garantizar la "recepción potente del extranjero" prometían eliminar "la emisora local o cercana" (Nora, Stromberg-Carlson). Esto sucedía porque la proliferación de emisoras de corto alcance a finales de la década de 1920 en España estaba produciendo una saturación en el dial, lo que a su vez provocaba interferencias entre emisoras.

\subsection{Cascos y auriculares}

Como ya hemos comentado la audición de los aparatos de galena se realizaba a través de auriculares y cascos, de ahí que en ocasiones la oferta fuera conjunta: "Siceola 1. Se complementa empleando un casco SICE"32. La diferencia entre auriculares y cascos era que los primeros se utilizaban en un oído, y los segundos en los dos oídos, y en consecuencia los primeros eran más asequibles. En la primera etapa investigada hemos encontrado auriculares cuyo precio oscilaba entre las 5 pesetas (Habana), 6,95 pesetas (Brunet), las 10 ptas. (Revo), las 11-12 ptas. (Ericsson).

En un anuncio ${ }^{33}$ de Cascos SICE podemos ver que los cascos se dividían en tres tipos según los ohmios, unidad de resistencia que indicaba la calidad de audición. Los más baratos (500 ohms.) tenían un precio de 10 pesetas, los medianos (2.000 ohms.) se ofertaban a 12 pesetas y los más caros (4.000 ohms.) costaban 30,50 ptas. Teniendo como referencia las gamas del anuncio podemos ver que la mayoría de los cascos anunciados se catalogaban en la gama intermedia: Hervor (15,50), Brunet $(19,60$ ptas.); y en la gama alta: Revo (25 ptas.), Ericsson $(26,50)$ y Telefunken $(35)$.

En el segundo periodo investigado la audición colectiva o libre redujo la aparición de anuncios de cascos y auriculares. Estos se siguieron vendiendo debido a dos motivos; primero, los nuevos receptores también permitían la posibilidad de la audición personalizada $y$, segundo, aunque los aparatos de galena estaban en proceso de desaparición todavía se seguían vendiendo. Así pues, de manera minoritaria, seguimos

\footnotetext{
31 (2-XI-1929: 20)

32 (1-VI-1925: 2)

33 (1-IX-1925: 2)
} 
encontrando anuncios de auriculares y cascos, como el reclamo de Telefunken ${ }^{34}$ donde expone "sus principales ventajas: Elegante presentación-Gran comodidad en la adaptación-Reproducción clara y perfecta-Fácil limpieza-Gran duración".

\subsection{Altavoces}

La aparición de los receptores de válvulas amplió el mercado de la radiotelefonía a un nuevo producto que supondría una gran fuente de ingresos a los fabricantes y comerciantes, si tenemos como referencia los numerosos anuncios encontrados y los altos precios de la gran mayoría. También es importante señalar que los aparatos integrados, (con el altavoz incorporado) no empezaron a comercializarse en España hasta el cambio de década de los veinte a los treinta, y que en los periodos investigados los altavoces eran un producto independiente, complementario, pero necesario para los aparatos receptores.

Existían tres gamas de altavoces según sus precios y dimensiones. En un anuncio de la marca Revo ${ }^{35}$ se especificaba que los altavoces grandes medían 55 centímetros de altura y 35 centímetros de diámetro, los de tipo mediano 49-26, y los inferiores o tipo "bebé" 31-18.

En la primera fase de estudio los altavoces más caros se vendían a un precio que superaban las 200 pesetas como el Altoparlante de Gaumont (260 ptas.), el Audivox de Sterling (225), Ericsson (200) y Brunet (200 ptas.). La gama media superaba el centenar de pesetas como el Altoparlante Lumiére (125 ptas.) los Ericsson (115), y el Baby de Sterling (110). Los altavoces más económicos costaban entre 50-100 pesetas como el Dinkie de Sterling (60 ptas.), el Brunet (79) y el Dragonfly de Amplion (50).

En la segunda fase la gama de altavoces se amplió como resultado de las innovaciones tecnológicas. El rango más alto lo encontramos en la marca Philips con sus altavoces electrodinámicos (500 ptas.) y altavoces electromagnéticos (225 ptas.) y junto a ellos la marca holandesa publicitaba sus modelos más baratos ( 85 y 75 pesetas). El precio medio lo encontramos en Radiolavox 30 (110 ptas.) y Punto Azul (150 ptas.).

\subsection{Válvulas}

Afirmaba Marconi que "el alma de un aparato de radio es la válvula" ${ }^{36}$. El ingeniero norteamericano Lee de Forest inventó en 1906 el audión, la primera válvula electrónica

\footnotetext{
34 (11-VIII-1929: 29)

${ }^{35}$ (26-VII-1925: 25)

${ }^{36}$ (1-VI-1925: 19)
} 
que tras años de experimentación y perfeccionamiento permitieron el desarrollo tecnológico del medio, y por ende del mercado radiofónico. En pocas palabras, las válvulas amplificaban las ondas recibidas y permitían la audición colectiva de los mensajes, condenando a los primitivos y defectuosos aparatos de galena. El principal defecto de las válvulas, común en todos los productos tecnológicos en etapas iniciales, era su vida útil, que lógicamente dependía del tiempo de uso del aparato. Su limitada caducidad provocaba la necesidad de su remplazo, y esto a su vez suponía una gran oportunidad de negocio para fabricantes y comerciantes. Junto a los reclamos de receptores y los altavoces, los anuncios de válvulas fueron los que tuvieron mayor presencia en la revista.

En la primera etapa las válvulas más baratas tenían un precio que oscilaba entre las 10 y las 15 pesetas. Las "piro-micro" de Castilla se vendían a 10 pesetas, las Elektron a 13,50 pesetas, las Radiotechnique y las Metal a 14, y las Telefunken tenían un precio de 15. Los precios de la gama media oscilaban en torno a las 20 pesetas, como las Philips $(18,5)$ y las Marconi (20), que "es más cara que las otras marcas por su gran duración y eficiencia en la recepción" ${ }^{37}$. Las más caras que hemos encontrado son las Radiotron de RCA que subían a 25-30 pesetas. En un anuncio ${ }^{38}$ de esta marca podemos leer: "Desde el 15 de octubre de 1921, fecha memorable de la primera emisión de Broadcasting, realizada en la Exposición de Industrias Eléctricas de Nueva York, por la RCA, ninguna válvula ha logrado igualar a las Radiotron. Por algo tiene tantas imitaciones".

En el segundo periodo investigado el negocio de las válvulas se multiplicó ya que los receptores más novedosos portaban seis y hasta ocho unidades, y aunque es de suponer que el avance tecnológico aumentó su vida útil, también es cierto que la gama de receptores se hizo más extensa aumentando el número de compradores y haciendo necesaria una mayor rotación en la renovación de las válvulas.

En esta fase aparecen nuevas marcas como Vatea, de la alemana Weslfalischer Metallhander, con una gran presencia publicitaria en la revista, y las válvulas Radio-Sol de la empresa de Antonio Castilla. Una mención especial merece la marca Tungsram que presentó de forma espectacular "la nueva válvula al bario metálico, algo esencialmente superior que se aparta de todo lo conocido hasta hoy". En el anuncio se describe las características de tamaña maravilla: "El bario metálico forma una homogeneidad absoluta con el filamento, siendo la emisión electrónica más intensa que la de los filamentos recubiertos de óxidos lo que determina una ampliación mayor y una sensibilidad considerablemente aumentada" 39 .

\footnotetext{
${ }^{37}$ (12-VII-1925: 17)

38 (4-IV-1926: 2)

39 (2-11-1929: 13)
} 
Hay un hecho que marca una gran diferencia entre la primera y la segunda etapa. En la primera los anunciantes incluían el precio de sus lámparas en los anuncios. En la segunda la mayoría omiten este dato, con pocas excepciones como Telefunken que ofrece esta información para toda su gama: seis tipos distintos con precios que oscilan entre las 24 pesetas la más barata y 80 la más cara.

\subsection{Otros}

A título informativo para ilustrar la gran variedad y complejidad de la industria radioeléctrica española en sus inicios haremos una sucinta relación de otros productos (y marcas) publicitados en la revista Ondas. Hasta la llegada de los receptores conectados a la red eléctrica, tanto los aparatos de galena como los de válvulas se alimentaban con baterías, acumuladores o pilas (Tudor, Zeiler, Hellesens, Pertrix, Nife, Nica, Leclanché). Las baterías necesitaban recargarse en rectificadores universales (Tungar) o grupos convertidores (Guernet).

Los galenistas podían construir sus aparatos con la galena sintética The Mighty Atom, que "se exporta a todo el mundo en cajitas precintadas que contienen dos trozos de mineral, pinzas, aguja especial protegida e instrucciones en español" ${ }^{\prime 4}$. Otra marca de galena muy publicitada fue Radiosita.

La llegada de los receptores eléctricos llevaba aparejado un problema: los diferentes voltajes que existían en España dependiendo de las distintas zonas geográficas y las diversas compañías eléctricas comercializadoras. Las potencias más comunes eran 110130-150-220 voltios. Para solucionar este problema y compatibilizar la potencia de un hogar al voltaje del aparato se necesitaba intercalar entre ambos un rectificador (Radiola) o un transformador (Philips, Ferranti).

Para aquellos usuarios que poseían un aparato de baterías o pilas, pero que no querían o podían adquirir uno eléctrico, tenían la oportunidad de conectar el viejo aparato a la red mediante una caja de alimentación (Gaumont).

Las tormentas podían constituir un peligro para integridad de los receptores. Las antenas podían recibir el impacto de los rayos y trasladar una súbita carga eléctrica a los aparatos y dañarlos. Para evitar estas situaciones Philips lanzó el "Derivatensiones que protegerá eficazmente su aparato contra toda descarga atmosférica pues automáticamente desviará a tierra cualquier sobretensión..."41.

${ }^{40}$ (5-VII-1925: 10)

${ }^{41}$ (29-VI-1929: 28) 
La Compañía Nacional de Electricidad detallaba el catálogo de la marca Kellogg, Switchboard and Supply donde se ofertaban: variómetros, acopladores variables, condensadores ley cuadrada, Neutrodous, Neutroformers, Jacks, clavijas, interruptores de baterías.

En otros anuncios también hemos encontrado: bobinas de bajas pérdidas (Nife), condensadores electrolíticos (Crosley), antisulfatadores (DAR), conmutatrices (Magneto, Janette), voltímetros (Ferranti).

\section{Conclusiones}

El mercado radioeléctrico español era en la década de los veinte altamente competitivo, como así demuestra la existencia de un gran número de marcas con presencia publicitaria en la revista Ondas. Esta competencia en el sector radio-producto contrasta con la concentración empresarial en el sector radio-servicio, que en el plazo de menos de cinco años, desde el nacimiento de Unión Radio en 1925, fue aglutinando casi todas las emisoras existentes en España hasta formar un monopolio del que solo escapaban algunas estaciones pequeñas y comercialmente irrelevantes.

El mercado español estaba dominado casi en su totalidad por las marcas extranjeras. Por un lado, las grandes corporaciones propietarias de Unión Radio, y por otro una gran diversidad de marcas de distinto tamaño, procedentes de un número reducido de países: EEUU, Reino Unido, Francia, Alemania y, en menor medida, Suecia. Frente a la abrumadora presencia de productos importados, destaca la labor de Antonio Castilla y su "producción netamente española", que junto a algunos receptores y cascos producidos por la SICE (con licencia norteamericana), suponían la escasa producción española en un mercado en continuo crecimiento en la segunda mitad de la década y al que se iban sumando paulatinamente más marcas foráneas. Bien es cierto que algunas tiendas especializadas ofrecían receptores artesanales manufacturados por los propios dueños o técnicos contratados, pero no tenían marca comercial y se vendían a un precio muy bajo, es decir que tenían una mínima relevancia competitiva.

Una de las grandes diferencias entre los dos periodos temporales estudiados es la complejidad técnica de los productos ofertados, sobre todo los receptores, en la primera etapa, y la evolución hacia la simplificación y la sencillez en la segunda. Si en 1925 para ser radioescucha el equipo mínimo necesario era un receptor, cascos (o auriculares), altavoz, baterías o pilas, y cargador de baterías, además de tener una remesa de válvulas de reemplazo, en 1930 los aparatos más modernos se enchufaban a la red y se manejaban con un mando. 
Esta primera diferencia nos lleva a una segunda: el público objetivo. En la primera etapa el destinatario era un público especializado con conocimientos técnicos en electrónica, a quien los anuncios se dirigían con detalladas explicaciones científicas sobre componentes y funcionamiento. La evolución del sector, sobre todo la escucha mediante altavoz, cambió los hábitos de consumo de radio y amplió los públicos hacia familias y el público femenino, modificando los mensajes publicitarios hacia lo emocional, abandonando los tecnicismos.

En este trabajo quedan apuntadas varias líneas de investigación para abordar en próximas investigaciones, como por ejemplo el estudio en profundidad de las estrategias publicitarias de los anunciantes, el impacto en el mercado radioeléctrico español de la crisis económica de 1929 analizando los primeros años de la década de los treinta, y la evolución del sector hasta el estallido de la guerra civil.

\section{Referencias bibliográficas}

Afuera, A. (2021a): Aquí Unión Radio. Crónica de la primera cadena española (19251939), Madrid, Cátedra.

- (2021b): “Orígenes de la autopublicidad radiofónica. Cómo vender un nuevo medio", en Documentación de Ciencias de la Información, no 44 (2), pp. 231-239.

Balsebre, A. (2001): Historia de la radio en España. Vol I. (1974-1939), Madrid, Cátedra.

Checa, A. (2000): Historia de la radio en Andalucía (1917-1978), Málaga, Fundación Unicaja.

Díaz, L. (1997): La radio en España. 1923-1997, Madrid, Alianza Editorial.

Faus, Á. (2007): La radio en España (1896-1977). Una historia documental, Madrid. Taurus.

Fernández Sande, M. (2006): Los orígenes de la radio en España. Volumen 2. La competencia entre Unión Radio y Radio Ibérica (1925-1927), Madrid, Fragua.

Franquet, R. Y Martí, J. M. (1985): La radio, de la telegrafía sin hilos a los satélites. (Cronología 1780-1984), Barcelona, Mitre.

Garitaonaindía, C. (1988): La radio en España (1923-1939). De altavoz musical a arma de propaganda, Madrid, Siglo XXI Editores.

López Vázquez, B. (2007): Publicidad emocional. Estrategias creativas, Madrid, ESIC Editorial. 
Salillas, J. M. (1988): Pioneros de la radio en España, Barcelona. Edición del autor.

Ventín Pereira, J.A., Rodríguez Barba, D., Fernández Sande, M. Y Peinado Miguel, F. (2000): 1924: el nacimiento de la programación radiofónica en España, Madrid, Editorial Temas Radiofónicos.

VV.AA. (1999): En el aire. 75 años de radio en España, Madrid, Promotora General de Revistas. 